\title{
Contesting Imagi-Nations of Nation and Region Through the use of Language in Saadat Hasan Manto's Toba Tek Singh
}

\section{Prakriti Arora ${ }^{1}$}

${ }^{1}$ M.A. Masters in English with Cultural Studies, Christ University (Deemed), Bengaluru,India

\begin{tabular}{|c|c|}
\hline Article Info & Abstract \\
\hline Article history: & Purpose: This research paper is an attempt to examine the themes of \\
\hline 11October 2020 & $\begin{array}{l}\text { colonialism, diaspora, and sufferance caused by the partition of India and } \\
\text { Pakistan through the lens of language and conflict in identities. The paner }\end{array}$ \\
\hline Accepted 23 November 2020 & also seeks to delve deeper upon the consequent breakdown of language as \\
\hline & depicted in the short-story Toba Tek Singh. \\
\hline Keywords: & Methodology/Approach: Textual analysis of mixed modes of reading. \\
\hline Nation, Region, & Findings: The short story effectively traced the turmoil and clamour \\
\hline Manto, Language, & enveloping the people afflicted by the events that followed the partition. Rich \\
\hline Identity & $\begin{array}{l}\text { with the themes of colonialism, diaspora and the horrors of the partition, the } \\
\text { text brought the issues being faced by the people in a way that they were }\end{array}$ \\
\hline Paper Type: & subtly intermeshed within the discourses of the inmates of the mental asylum, \\
\hline Research Article & which was where the story was situated. The text, characteristically a short \\
\hline Corresponding Author: & $\begin{array}{l}\text { story, reflects the feelings of the people that sprouted during and after the } \\
\text { partition in a nonchalant way. This subtlety and novelty of expression }\end{array}$ \\
\hline Prakriti Arora & $\begin{array}{l}\text { questions the basis of a 'nation'. } \\
\text { Conclusion: The short-story revolves around the accounts of a number of }\end{array}$ \\
\hline $\begin{array}{l}\text { Email: } \\
\text { prakritiarora96@gmail.com }\end{array}$ & $\begin{array}{l}\text { inmates who are seemingly devastated by the new changes and the new ways } \\
\text { of labelling lands. Even if they are able to make sense of this imposed } \\
\text { change, they refuse to reason with it completely as a few of them must be } \\
\text { relocated, which would consequently distance them from their friends. }\end{array}$ \\
\hline
\end{tabular}

\section{Introduction}

The Partition of India and Pakistan in the year 1947 is not only looked back as a traumatic memory but also as an event that gave rise to a considerable number of writings in languages like Hindi, Punjabi and Urdu. The writers at the time expressed their anger and disapproval by interestingly employing words to their benefit. One such famous writer was Saadat Hasan Manto. Born in British India, his own identity was a subject to constant challenges posed by "shifting boundaries" of the nation. One of the crucial and influential works from his career that traced this turmoil was Toba Tek Singh. A short story, originally written in Urdu language, addressed the consequences faced by the inmates of a mental asylum in Lahore. Manto cleverly blurred the boundaries between a 'mad' world and a sane world, by questioning the latter.

This paper poses questions such as, what is a nation? What are the effects of defining 'nation', 'region' and 'boundaries'? To establish the authorial intervention and intersection with the source text to describe the trauma, the paper also aims to look closely at the representation in the latest film release, Manto. The text projects an interesting aspect to read the contesting identities which transpire as a result. 


\section{Methodology/Approach}

The primary text for this paper is interpreted in a textual analysis involving mixed modes of reading. The analysis is also substantiated with secondary sources.

\section{Analysis and Results}

A cartographer's pen is a rather powerful instrument. The seemingly harmless lines that he draws transform into divisive boundaries, offering identities to a few and stealing the same from the others. The concept of 'boundaries' as a premise to dwell upon the idea of nation and region may not be entirely novel but it is still intriguing. From its very etymology, the meaning implies something that bounds, often a defined area. It gives shape to a land, an enclosure. When this understanding is juxtaposed with the design of 'shifting boundaries' it adds another dimension to the discussion of what is defined as 'nation'. It moves forward to imply that a borderline which was considered stationary up until the moment can potentially shift and change. In this sense, what is imagined as a nation or a region can also be subjected to contestation. As finely put by essayist Stephen G. Tomblin in his work "Shifting Boundaries and Borderlands Discourses" also, "boundaries are becoming more porous and new relationships are being ordained" (Tomblin 194); and the easiest way to see this being realised is through the lens of language and literature. The interaction between cultures or inversely, the distress that these shifts cause are beautifully portrayed by the renowned Urdu writer Saadat Hasan Manto's work, Toba Tek Singh.

Complementing this, scholars such as Ernst Renan and Benedict Anderson have also deliberated substantially upon the issue of shifting boundaries. The foundational argument remains that a nation is "a socially constructed community, imagined by the people who perceive themselves as part of a particular group" (Anderson 49). Through Manto's short story, ideas like these are explored and the overarching imaginations perpetrated by the ones in power are challenged.

This research paper, therefore, seeks to delve deeper into the usage of language and its consequent breakdown to highlight the changing imaginations about the concept of 'nation' and 'region'. It then becomes engrossing to see how the ideas attached with the aforementioned terms transgress and reshape according to the experiences of the people. The paper also aims to present a discourse analysis with the assistance from Nandita Das's latest release, Manto, to understand the subtlety in the expression of extreme violence and despair such that it is almost rendered silent and non-existent. Saadat Hassan Manto is often seen to twist and turn the words as if taking the metaphorical shield of describing his identity and sense of belongingness being twisted and turned by the functioning political powers. Lastly, this gives rise to questioning the established understanding about colonialism and the identities it gives birth to, which demand to be examined in a new light.

To understand this, it must be considered how there are certain events in history which can instantaneously swarm someone with innumerable memories only by a slight allusion. The Partition of present-day India and Pakistan characteristically falls under this category. It is an event which binds together a major section of the Indian population, and 
covers them under one umbrella with the spokes pointing towards 'revolution', 'freedom' and 'nation'.

The aforementioned, seemingly innocent terms not only ensued from the division of erstwhile Bharatvarsa but also gave rise to a considerable number of writings in languages like Hindi, Punjabi and Urdu. In a time when people were grappling with the constantly altering realities and changes in the faces of political authorities and figures, literature came across as a force to reckon with. It was almost as if language and literature provided a mesh net for the people to bounce back upon, to help them comprehend and articulate their feelings and internal struggles insinuated by a cartographer's line, which is famously known as Radcliffe Line. The confusion and chaos was largely permeable in Manto's works and one of the most famous outcomes of the trauma and atrocities faced by the people emerged in the form of Toba Tek Singh.

Manto's Toba Tek Singh was published for the first time in the year1953, originally in Urdu language, in Savera magazine. By that year, Manto had already moved to Pakistan, leaving Bombay behind, a city with which he had nurtured the feeling of belongingness, a city where not only his career but his life, at large, was thriving. The text, Toba Tek Singh, is approximately set in the years 1949-50, and discusses the inmates of a "lunatic asylum" in Lahore, Pakistan. It begins with the triviality of transfer of the inmates of the asylum based on their religious affiliations. The Sikhs and Hindus must be sent to Hindustan and the Muslims are to be retained in Pakistan. The story becomes like a thread sewing two pieces of cloth. On one end, the inmates are being forced to shift without any regard to their choice and inclination, and on the other end, Manto must leave India regardless of being a non-practicing Muslim. In this way, the concerns and anger against the ruling governments that find little or no space of representation in real life get penned as a sarcastic remark in the story.

The short-story revolves around the accounts of a number of inmates who are seemingly devastated by these changes and the new ways of labelling lands. Even if they are able to make sense of this imposed change, they refuse to reason with it completely as a few of them must be relocated, which would consequently distance them from their friends. The character highlighted in the story is named Bishan Singhwho comes from a village called Toba Tek Singh. He is famous for not having closed his eyes to rest for the last fifteen years. Instead he stands at all times, and when tired, barely leans against a wall. The character "continually mutters variations of the nonsensical Punjabi refrain, "O pardi ginger axe di bhedhiana di moongdi dal di laltain" (Alter 96).

The tale of Bishan Singh revolves around his inquiries about the "updated" location of his village which is why he is soon recognized and called out as Toba Tek Singh. The story takes an interesting turn when the inmates are being processed at Wagah Border checkpoint and Bishan Singh finally manages to realize that his village falls on the other side of the boundary, which is Pakistan, from where he is being deported. He refuses to move or cross the border. This refusal is somewhat parallel to the one that Manto feels in real life. As artistically articulated in Nandita Das's directorial, Manto, there is a clear denial in the protagonist's mind to move away from Bombay. His optimism towards the independence soars higher than the differences being carefully cultivated between Hindus and Muslims.

The story concludes on the point when Bhishan Singh utters a piercing cry and is found lying on the ground, "prostrate". On one side of him is Hindustan and on the other, 
Pakistan, but in the middle, "on a stretch of land that had no name, lay Toba Tek Singh" (Manto 19). The ending leaves a lasting impression. Bishan Singh almost mirrors the plight and distress of Manto. The piercing cry can be possibly read as the last work by Manto, his final word. He dies the year Toba Tek Singh's last edition is published. However, this piercing cry and the usage of language open a way for various interpretations. If Manto is seen able to articulate his suffering and pain through his pen, Bhishan Singh is completely unable to make sense of the changing world around him. He is a man of few words, literally and in his dying moment, even they leave his side. This inability to articulate mixed with agony and sadness is probably best described by the aching cry. A state in which words hold no meaning and no space has a deeper impact on the readers, as compared to hurling comments or expressing well-articulated feelings.

The text, characteristically a short story, has been largely acclaimed to have represented the feelings of the people that sprouted during the partition in a nonchalant way. This subtlety and novelty of expression questions the basis of a 'nation'. To understand this in depth, Toba Tek Singh can also be looked parallelly with Ernst Renan's work in "What is a Nation?". The primary argument in the essay delineates that the idea of a nation is a new construct. "It is a construction - a social construction, determined by the consent of the people" (Renan 2). If the citizens are the ones to determine the meaning of the nation, then the dominant notions established by the ones in power, namely political or military forces, stand challenged. In such a manner two conflicting definitions are made to fight for power and recognition. Moreover, the heteronormativity adopted by the political forces is also questioned, because multitudinous and various voices emphasise their existence. This encourages an enriched emphasis on the people and the manner in which they constitute and construct the nation, and what it means to them. The essence of the nation then becomes something that all of its individual members have a great deal in common (Renan 3). This development and establishment of the understanding of a common ground makes it possible for them to forget certain differences also to be able to come together in unity. What Renan says is highlighted in the story in the manner in which the inmates have developed a friendship and feeling of belongingness in the company of each other. If observed carefully, they are largely unaffected by the freedom movements and revolutions occurring outside the asylum. Moreover, the Partition of India and Pakistan also does not affect them until their segregation is demanded by the authorities functioning outside the asylum. They might not have willingly come collectively to a particular place to live in harmony but they have certainly adapted themselves to the environment and their neighbours. Therefore, when this nation or microcosm of a nation is refused to be able to hold its ground, the sense of communal living regresses back to being a mere 'mental asylum'.

The above arguments relating to nation and division on the basis of religion find a rather beautiful and simplistic representation in the story when a Sikh lunatic asks another Sikh, "Sardarji, why are we being sent to Hindustan? We can't even speak their language" (Manto 14). The basic idea of language, as even propagated by Gayatri ChakrovartySpivak, is that it is a means of meaning construction. If the people are invested with a sense of fear that the land they are being moved to is so alien to them that they won't be able to conduct the simplest of things, that is to communicate, then what is the benefit of such a Partition? The alienation from a land that is being forced upon them as their nation becomes so ironical in

Copyright (C) 2020, Prakriti Arora. This work is licensed under a Creative Commons Attribution 4.0 
this case because it means nothing to them. They would rather associate the feeling of 'homeliness' with an area that is beyond the realms of division-a mental asylum-a place where they feel free to communicate and are able to comprehend meaning, to say the least.

The points elucidated by Renan are further explored in Benedict Anderson's work "Imagined Communities" where his understanding of a 'nation' implies "a socially constructed community, imagined by the people who perceive themselves as part of a particular group" (49). This argument concretizes the observation made above about the inmates uniting together and coming to a stage where they are all able to consider themselves as a part of one community. Ironically, however, the newly formed governments of both the divided nations and the political forces have little or no feeling of belongingness with the inmates of the asylum. The inmates, in this way, are bereft off their identities for they are now imposed with the new ones, as approved by the authoritarians.

In Toba Tek Singh, the asylum becomes a microcosm of a nation. There is a visible diversity in its constitution, just as Renan discusses that different states are characterized by "fusion of the populations that comprise them" (2). The inmates are from all walks of life, some have even been murderers. Additionally, the confusion increases in their minds, for a few of them are neither Hindu or Sikh, nor Muslim but Anglo-Indians. These stringent impositions of the definition of a nation and the area that it encloses under its name triggers hysteria and crisis. It is almost as if everything is seen as either black or white, and no one seems to have a realization to acknowledge the grey areas. Also, the asylum is a place that is enclosed by boundaries. When the effects of partition hit the asylum, as a repercussion, these boundaries are bound to shift. This shift results in an alteration of identities, just like they alter Manto's identity. A non-practicing Muslim is forced to move to Pakistan and a nonbeliever Hindu is forced to find refuge in India. It becomes more or less inconsequent what they believe in or what they hold true to their identities. The protests that they may mouth meet a deaf ear. Bhishan Singh's protests to not cross the border are met by ignorance by the guards, so much so, they let him be at the border while they take care of the others.

The text is rich with the themes of colonialism, diaspora and illustrates the struggles faced by the people. The themes are intermeshed within the discourses of the inmates of the mental asylum, where the story is situated, which sets it apart. An essential point discussed in Anderson's work is that the nation becomes an imagined entity primarily because "the members of even the smallest nation will never know most of their fellow-members...yet in the minds of each lives the image of their communion" (Anderson 49). This argument may stand positively in respect of the political powers and the decision makers for they consider the inmates of a mental asylum as part of their newly constructed nation. However, it also becomes equally contradictory because this way of inclusiveness is highly religion-driven. The fact that madness is largely considered a disease and the people who suffer this are rather marginalized until there is a need to establish a community, albeit artificial and somewhat inconsiderate. The fact that the inmates may be uncomfortable and unsupportive of this idea of segregation does not meet any acknowledgment or consideration. On the other hand, the inmates of the mental asylum have formed a more ideal nation among themselves. There is an obvious sense of community invested in each which makes them climb on trees or rebel at the first opportunity. Amongst themselves, they communicate and develop a sense of camaraderie. 
Additionally, Manto's use of language to exemplify this hysteria makes the text all the more interesting. According to Michel Foucault from Archaeology of Knowledge and the Discourse on Language, language is the act of meaning production. It is more or less literally followed in Toba Tek Singh also. In this manner, it constitutes both the literal meaning as well as the connotative meaning. What is seen as the mere breakdown of language, actually holds someundertones. Bishan Singh's "oper di gundi..." is rather refused to be read as something beyond confusion and chaos. Perhaps the regular enunciation of the same phrase indicates his longing for a place which he associates with the idea of 'home'. The breakdown of language also stands as a strong remark against the Partition. It must not be negated that this way of writing could possibly be Manto's way of subtly throwing light upon the atrocities faced by the people. The violence against men, women and children, looting, rapes and mass murder instigated by this division are so heinous that the ones who have faced this or the people related to them have gone through it have had such an impact that they are rendered speechless. This could also be a way of representing the author's own feelings regarding the Partition. In the latest Nandita Das's, Manto, the personal life of the author is beautifully explored. This way, it becomes safe to establish that this short story isManto's outlet to his emotions and his impressions of 1947. He is left behind in Bombay by his family for they decide to move to Pakistan but his feelings of belongingness truly rest with a place which now falls under the Indian Territory, as opposed to his religious affiliations. On having reluctantly moved to Pakistan, this feeling of belongingness gets replaced by a feeling of longing. A constant longing that causes madness in him. However, this madness may be to reside in a place he feels most connected to.

It is even more significant to see Manto drawing a criticism on the 'sane' world under the garb of a madhouse or an insane world. There is an obvious questioning on the sanity of the ones in power for they seem to be drunk in power and authority to make decisions for everyone just because they stand at a privileged position. The concept of sanity is somewhat parallel to order, or conducting things and actions in order. When this order gets disrupted, the idea of insanity emerges. The depiction of this proposition is best explained through the loss of order in language. The repeated enunciation "oper di gundi..." constitutes a disordered language. A phrase which lacks grammar which can be easily associated with the larger scheme of order. Thus insanity becomes something that is disordered. But it is up to the readers to question whether excess of order, as practiced in the form of Partition and construction of boundaries, isn't something which defines insanity more accurately?

In a thought compelling review of the film, Manto, Anna MM Vetticad from Firstpost remarks how it provides "a running commentary on the heart-breaking socio-economic realities of Partition." The work may be classified as a 'film noir' for it draws a critique on the fatality of the Partition. The optimism of the Independence of the Indian subcontinent is soon coloured with pessimism and cynicism because of the forced displacement of people and the riots that perpetrate this movement furthermore. It is very interesting to see how the enunciation of certain words are so powerful that they have the ability to persuade even a non-practising Muslim also to move to Pakistan. In the film, post-Independence, riots break out in Manto's beloved city - Bombay. A tensed unfolding of this scenario leads one of his closest friends, Shyam Chadda to comment on the raging attacks by the Muslim mob in Pakistan that if he had to, he could have even killed Manto for revenge. This line spoken out 
of sheer anger and distress makes Manto realise the importance of his religious identity and the danger hanging around his neck like a dagger that may be dropped any moment. The repercussion of this verbal feud is that the protagonist takes an impulsive decision to move to Pakistan. These words not only leave a mark on him, but also force him to negotiate with a city with burnt buildings and abandoned houses, oozing the feelings of isolation and betrayal.

In the film also, language has been employed to a very interesting use for it interweaves the stories penned by Manto in the film narrative. The fact that his distress from Partition is inseparable from his work becomes apparent through the filming of the short story Toba Tek Singh. Suffering from severe alcohol addiction, he finally admits himself to an alcohol rehabilitation centre in Lahore Mental Hospital which subsequently gives birth to the very famous short story. Interestingly, in this mental hospital, there is an inmate who repeats the same gibberish as Bhishan Singh. Manto's predicament is no different than the latter's for the wordless and helpless man ends up dying in a no-man's land. The manner in which Nandita Das has directed this sequence is intermeshed with the author's life so effortlessly that it leaves a lasting impression on the minds of the viewers. It is so moving that the viewers can understand the pain and devastation that Manto goes through during the last days of his life. All he is left with are words and they seem like his only coping mechanism. His devastated state of mind, however, leaves the viewers and the readers with some of the most compelling short stories, which actually trace his own life.

To add to this, the reply to the remark by his friend, Shyam, in the film that "I am Muslim enough that I could be killed for it" is a poignant statement for in both Manto and Bhishan Singh's lives, religious identities become the defining element for their belongingness to a place. The clear articulation of the situation in Manto's case is inversely proportionate to the inarticulate and confusing gibberish in Singh's. However, one thing is established that in both the instances the movement is forced and undertaken completely out of unwillingness. The boundaries shift and like a character says in Toba Tek Singh they didn't even order for it.

\section{Conclusion}

This interwoven discourse of the short story Toba Tek Singh and Manto's personal life give birth to a set of challenges that can be posed to, what gets defined as, nation and region. Since, it is a life of an acclaimed author that is under consideration, there is no better way to visualize the aforementioned through the use of language. It is best explored through the characters residing in the mental asylum. Seeking refuge from the outside world, they are ultimately forced by it to move away to separate lands. If the language is used to articulate the distress, pain and anguish that these inmates are going through then the breakdown of language takes the form of indescribable agony faced by Manto himself. The words are twisted as if to portray how their identities are being twisted, without their consent. The short story becomes a critique on the actions of the authoritarians who displace a helpless man from his 'home' to be able to stay alive amid the riots. The piercing shriek and the breakdown of language resemble the torture and fear caused by the partition being rendered silent. In the end, a single cartographer's line even slices language into orderly and disorderly, articulate and inarticulate, sanity and insanity. 


\section{Conflict of Interest}

The author of the article declares no conflict of interest.

Funding

None

Work Cited

Thomas, Maria. "Bombay heart, Urdu ink: A guide to reading Saadat Hasan Manto." Quartz India. September, 2018. Accessed on: 14 November 2018.https://qz.com/india/1396544/mantos-urdu-writings-on-indias-partition-bombaybollywood/

Manto, Saadat Hasan. Toba Tek Singh. Manoa, Vol. 19, No. 1, Crossing Over: Partition Literature from India, Pakistan, and Bangladesh (Summer, 2007), pp. 14-19.Das, Nandita. Manto. 2018. https://www.jstor.org/stable/i395494

Tomblin, Stephen G. "Shifting Boundaries and Borderlands Discourses." Acadiensis, Vol. 23, No. 1, Autumn 1993, pp. 194-203. http://www.jstor.org/stable/30303479

Alter, Stephen. "Madness and Partition: The Short Stories of Saadat Hasan Manto." Alif: Journal of Comparative Poetics, no. 14, Madness and Civilization, 1994, pp. 91-100. https://doi.org/10.2307/521767

Renan, Ernst. "What is a Nation?” Text of a Conference, Sorbonne, 11 March 1882, Translated by: Ethan Rundell, pp. 1-11

Anderson, Benedict. "Imagined Communities." A Compilation of Readings for Cultural Debates, June-September 2017, pp. 48-58.

Koves, Margit. "Telling Stories of Partition and War: Saadat Hasan Manto and Istvan Orkeny." Economic and Political Weekly(1997): 2147-2153. https://www.jstor.org/stable/4405763

Vetticad, Anna MM. "Manto Movie Review: Nawazuddin Siddiqui is the best he has ever been in Nandita Das' stirring portrait of a genius." Firstpost, September 2018. Accessed on: 29 November, 2018.https://www.firstpost.com/entertainment/mantomovie-review-nawazuddin-siddiqui-is-the-best-he-has-ever-been-in-nandita-dasstirring-portrait-of-a-genius-5231401.html

Foucault, Michel. "Introduction." The Archaeology of Knowledge and the Discourse on Language, Pantheon Books, New York, 19072, pp. 3-20.

Siddiqui, Mohammad Asim. "Saadat Hasan Manto's Poetics of Resistance." Social Scientist 40.11/12 (2012): 17-29. https://www.jstor.org/stable/23338867

Tiwari, Sudha. "Memories of Partition: Revisiting Saadat Hasan Manto." Economic and Political weekly (2013): 50-58. https://www.jstor.org/stable/23527974

Young, Deborah. "Manto: Film Review." Cannes, 2018. Accessed on” 29 November 2018.https://support.google.com/websearch/answer/7220196?p=AMP\&visit_id=6367 $\underline{90685168455102-593231825 \& \mathrm{rd}=1}$ 